\title{
O desenvolvimento de brincadeiras criativas no contexto dos parquinhos públicos
}

\section{The development of creative play in the context of public playground}

\section{El desarrollo del juego creative en el context de parques infantiles públicos}

\author{
Amanda Santos de Souza \\ Universidade Salvador - UNIFACS, Salvador, Bahia, Brasil \\ Paula Sanders Pereira Pinto \\ Universidade Salvador - UNIFACS, Salvador, Bahia, Brasil
}

\begin{abstract}
RESUMO
O objetivo deste estudo foi investigar o desenvolvimento de brincadeiras criativas em um parquinho público localizado na cidade de Salvador (BA). Considera-se uso criativo todas as variações do seu uso original. Trata-se de um estudo exploratório, descritivo e analítico, dividido em duas etapas, no qual foram identificadas as brincadeiras criativas mais comuns antes e depois da reforma do parquinho. Os dados foram coletados através de sessões de observação de brincadeiras e analisados qualitativamente. Verificou-se que a brincadeira criativa foi utilizada pelas crianças antes e após a reforma do parquinho. Antes da reforma, o uso criativo foi feito logo no início das brincadeiras; depois, este tipo de exploração ocorreu após o uso funcional do espaço e dos equipamentos, uma vez que estavam em melhores condições de uso. Ressalta-se a necessidade da construção de parquinhos públicos mais atrativos e que estimulem a criatividade de uma maneira segura, considerando os perigos que um espaço danificado pode trazer para a saúde das crianças.
\end{abstract}

Palavras chave: uso criativo, brincar, infância.

\section{ABSTRACT}

The aim of this study was to investigate the development of creative play in a public playground located in the city of Salvador (BA). It is considered as creative use all the variations of its original use. This is an exploratory, descriptive and analytical study, divided into two stages, in which they identified the most common creative play before and after the playground reform. The data was collected through the plays observation sessions and it was analyzed qualitatively. It was found that the creative play was used by the children before and after the playground's reform. Before the reform, the creative use happened as soon as they started to play. After the reform, this type of exploration occurred after the functional use of the space and equipments, since they were in better conditions to be used. It emphasizes the need to build more attractive public playgrounds and encourage 
creativity in a safe manner, considering the dangers that a damaged space can bring to the health of children.

Keywords: creative use, play, childhood.

\section{RESUMEN}

El objetivo de este estudio fue investigar el desenvolvimiento de juegos creativos en un parque público localizado en la ciudad de Salvador, en bahía. Considerase uso creativo todas las variaciones de su uso original. Tratase de un estudio exploratorio descriptivo y analítico, dividido en dos etapas, la cual fueron identificadas a juegos creativos más comunes antes y después de reformar el parque. Los datos fueron recolectados por sesiones de observaciones de de juegos y analizados cualitativamente. Se encontró que el uso creativo fue utilizado por los niños antes y después de la reforma del parque infantil. Antes de la reforma, el uso creativo se hizo en al comienzo del juego. Después de la reforma, este tipo de exploración se produjo después de que el uso funcional de espacio y equipo, una vez que estaban en mejores condiciones de uso. Se hace hincapié en la necesidad de la construcción de parques infantiles públicos más atractivos y que vengan a fomentar la creatividad con seguridad, teniendo en cuenta los peligros que un espacio dañado puede aportar a la salud de los niños.

Palabras claves: uso creativo, jugar, infancia.

\section{Introdução}

A brincadeira é percebida pela Psicologia Evolucionista como um conjunto de comportamentos relacionados e complexos (Pellegrini \& Smith, 1998), que variam de acordo com o contexto educacional, sociocultural e político-econômico circunscritos ao brincante, que são regidos também pelo seu aspecto motivacional e subjetivo. Trata-se de um fenômeno universal, complexo e difícil de ser conceituado de uma única forma, visto que é objeto de estudo de diversos autores (Bichara, Lordelo, Carvalho \& Otta, 2009). Sua relevância para o desenvolvimento humano se deve ao fato de que a brincadeira possibilita que a criança desenvolva habilidades variadas, a nível motor, cognitivo, emocional e social, além de possibilitar a vivência de situações novas que aprimoram sua noção de Eu e ampliam seu contato com a realidade, seja através da experiência lúdica ou da criatividade, o que a prepara para lidar com o novo e inesperado de forma produtiva (Fagen, 1981; Siaulys, 2005).

Tendo em vista que a criança constrói seu repertório comportamental ao longo do próprio desenvolvimento e de acordo com as experiências vividas, as brincadeiras e demais atividades lúdicas podem funcionar como um veículo de aquisição de habilidades que serão úteis futuramente (Bjorklund, 1997; Vieira \& Sartório, 2002), uma vez que, na brincadeira, a criança pode experimentar, criar, conhecer e/ou simular situações (reais ou não), que vão promover autoconhecimento e gerar uma construção simbólica do que está sendo vivenciado. 
Segundo Moraes e Otta (2003), o brincar acontece no que se chama Zona Lúdica, que possui elementos característicos: a criança e sua subjetividade, o espaço geográfico em que está inserida e o espaço temporal. Estes espaços vão se construindo e se modificando de acordo com as necessidades e possibilidades dos contextos sóciohistóricos nos quais estão inseridas. Até o século XIX, por exemplo, a rua era o principal espaço de socialização, sendo bastante comum sua exploração pelas crianças para o desenvolvimento de brincadeiras. Entretanto, as diversas mudanças no âmbito social, político, econômico e cultural que ocorreram nos últimos anos promoveram um significativo crescimento industrial, das cidades e da população, o que resultou no aumento da criminalidade e tornou a rua um espaço perigoso e inadequado para o desenvolvimento de brincadeiras (Luz, Raymundo \& Kuhnen, 2010; Oliveira, 2004).

Desse modo, tornou-se necessário pensar na construção de espaços mais apropriados para o lazer infantil. Influenciado pelo movimento "playground movement", surgido nos Estados Unidos no final do século XIX, o urbanismo brasileiro adotou o parquinho público como modelo de espaço para as crianças brincarem coletivamente (Niemeyer, 2005; Santos, Nascimento \& Pinto, 2014). Considerado um contexto propício ao desenvolvimento, estes espaços possuem equipamentos variados que estimulam processos cognitivos, motores e sociais da criança, sendo, muitas vezes, seu primeiro espaço de socialização (Luz et al., 2010; Oliveira, 2004).

Os parquinhos podem ser considerados, segundo Rasmussen (2004), como "lugares para crianças", uma vez que são espaços "ideais", construídos por adultos e destinados à criança, oferecendo-a equipamentos com funções específicas a serem utilizados na brincadeira e que podem direcionar e limitar o brincar. Contudo, na medida em que as crianças se apropriam desses espaços e os utilizam de uma forma alternativa àquela originalmente proposta, há uma transformação do "/ugar para crianças" em um "/ugar de criança".

Através da criatividade, a criança explora o parquinho público de uma maneira diferente e origina o que denominamos de brincadeira criativa, que acontece a partir do uso criativo dos equipamentos do parquinho, e que é entendida como uma brincadeira não esperada pelos adultos no momento em que planejam e constroem estes espaços (Vygotsky, 1998). De acordo com Vygotsky (1998), a partir do brinquedo a criança deixa de agir sob uma esfera externa (visual, tátil, etc.) e aprende a agir sob a esfera cognitiva. Assim, ela passa a depender muito mais das suas motivações e das tendências internas do que dos estímulos do objeto.

Diante disso, a criança passa a dirigir suas ações por meio do significado subjetivo que atribui a dada situação, pois começa a agir perante o objeto de uma forma diferente daquela que é esperada. 
Isso acontece porque, ao brincar, a criança separa o pensamento do objeto e sua ação passa a surgir das ideias próprias, e não mais dos objetos em si. Acontece, por exemplo, quando um pedaço de madeira se torna um cavalo e uma gangorra se torna uma ponte. Ao relacionar-se com o significado, a criança altera o sentido e a funcionalidade dos objetos e, assim, faz o uso criativo dos mesmos (Vygotsky, 1998).

Dentre os diversos aspectos da brincadeira, dois em especial estão diretamente relacionados à elaboração de formas alternativas de brincar e ao uso criativo: a tentativa de combinações, que possibilita ao indivíduo a oportunidade de estabelecimento de padrões motores complexos, fenômeno caracterizado pela variação de determinada habilidade em outros contextos, no qual o aspecto lúdico do uso de instrumentos caracteriza-se por um maior interesse nos meios em detrimento da finalidade e do ato em si (Bruner, 1976 citado por Brougère, 1998); e a preparação do indivíduo para o inesperado (Spinka, Newberry \& Bekoff, 2001), que resulta numa maior versatilidade de movimentos usados para lidar com possíveis eventos súbitos e que propicia respostas criativas diante de estímulos ambientais.

O uso criativo pode ser entendido como uma forma de modificação do espaço para criança em espaço de criança, que a criança pode realizar a partir da apropriação do ambiente mediante a sua exploração diferenciada. De acordo com Pol (1996), a apropriação consiste na transformação de um espaço a partir da sua significação, bem como o reconhecimento deste espaço transformado, que reflete a continuidade desta nova identidade construída.

Corsaro (2011) acredita que as crianças compreendem a possibilidade de modificação das rotinas habituais e óbvias das quais fazem parte, pois embora as regras previsíveis as ofereçam segurança, elas se empenham em experimentar o novo. Assim, o desenvolvimento do uso criativo nos parquinhos ocorre a partir da própria vontade da criança de modificar as normas impostas pela própria função dos equipamentos que constituem esses espaços.

Ao apresentar o conceito de reprodução interpretativa, Corsaro (2009) contribuiu para a compreensão da relação entre a brincadeira e a cultura. Segundo o autor, o termo reprodução refere-se àquilo que vai além da imitação e da internalização da cultura mais ampla, ou seja, diz respeito ao entendimento de que, ao brincar, a criança contribui ativamente para a produção e mudança cultural, tendo em vista que as brincadeiras desenvolvidas são afetadas pelo contexto sociocultural em que ela está inserida e promovem a sua reinterpretação e transformação.

Esse conceito promove a ideia inovadora de que a criança é um agente de participação e construção social, já que, através da brincadeira, ela apreende de forma criativa a cultura maior e o 
mundo adulto e, assim, passa a produzir cultura de forma a atender seus interesses enquanto criança (Corsaro, 2009). Sendo assim, a criança passa a ser considerada um participante ativo e coconstrutor de seu próprio desenvolvimento (Corsaro, 2006 citado por Seixas, Becker \& Bichara, 2012).

Considerando a influência do espaço físico no desenvolvimento das brincadeiras, (Cotrim \& Bichara, 2013) entende-se que quanto mais atrativo e interessante for um parquinho, maiores serão as possibilidades de utilização criativa do mesmo. Em sua pesquisa, Santos et al. (2014) trouxeram importantes considerações sobre a situação dos parquinhos públicos na cidade de Salvador-BA ao relatarem condições precárias de segurança dos espaços e seus equipamentos; baixa atratividade; pouca diversidade de brinquedos e cores e dificuldades de acessibilidade.

Ainda pensando nesse contexto de desenvolvimento, Johnson, Christie e Yawey (1999) distinguiram três principais tipos de parquinho: (1) os parquinhos tradicionais, que possuem equipamentos mais básicos e isolados, e cujas funções são prédeterminadas; (2) os parquinhos contemporâneos, cujos equipamentos são mais atrativos e variados, feitos de diferentes tipos de material, e que estimulam um pouco mais a criatividade do brincante; (3) e os parquinhos de aventura, no qual os equipamentos são feitos de materiais reciclados, de caráter mais abstrato, com área livre constituída por um ambiente natural, e que favorece a imaginação.

Tendo em vista a relevância da brincadeira para o desenvolvimento infantil, bem como a constante prática do uso criativo nos espaços de lazer destinados às crianças, buscou-se, neste trabalho, compreender o desenvolvimento de brincadeiras criativas em um parquinho público da cidade de Salvador-BA nos períodos pré e pós reforma do espaço pela prefeitura do município.

\section{Método}

Trata-se de um estudo exploratório, descritivo e analítico, que foi realizado em duas etapas, onde foram observadas brincadeiras de crianças em um parquinho público antes e após a reforma do mesmo pela prefeitura do município. Este pode ser considerado um parquinho contemporâneo (Johnson et al., 1999), é feito de madeira e possui os seguintes equipamentos: dois módulos ligados por uma ponte - cada um contendo uma casinha -; dois escorregadores; uma barra de ferro; duas gangorras; duas escadas acopladas aos módulos, localizadas em suas extremidades. Após a reforma do espaço um carrossel foi incluído. A área de livre circulação deste parquinho é delimitada pelo solo de areia que o constitui, sendo considerada 
estreita na medida em que não compreende espaço suficiente para que as crianças se envolvam em brincadeiras mais turbulentas, de expansão corporal, como correr, por exemplo. Além disso, os brinquedos se encontram em grande proximidade uns dos outros, 0 que contribui para a dificuldade de desenvolvimento das brincadeiras anteriormente citadas. Os desenhos esquemáticos a seguir ilustram 0 referido espaço antes e após a reforma (Figuras 1 e 2):

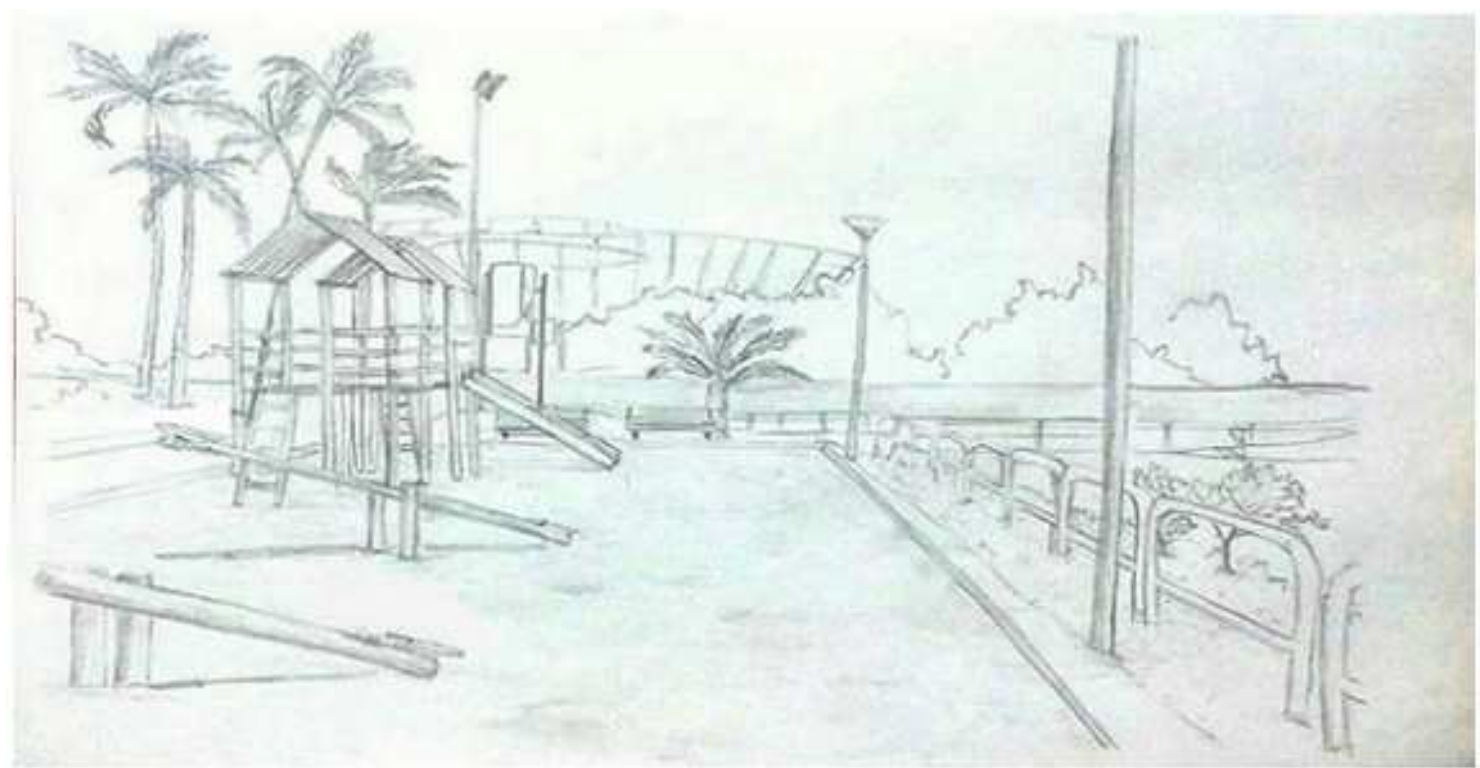

Figura 1: Desenho do parquinho antes da reforma. Ilustração: Mariana L. L. Q. Fonseca

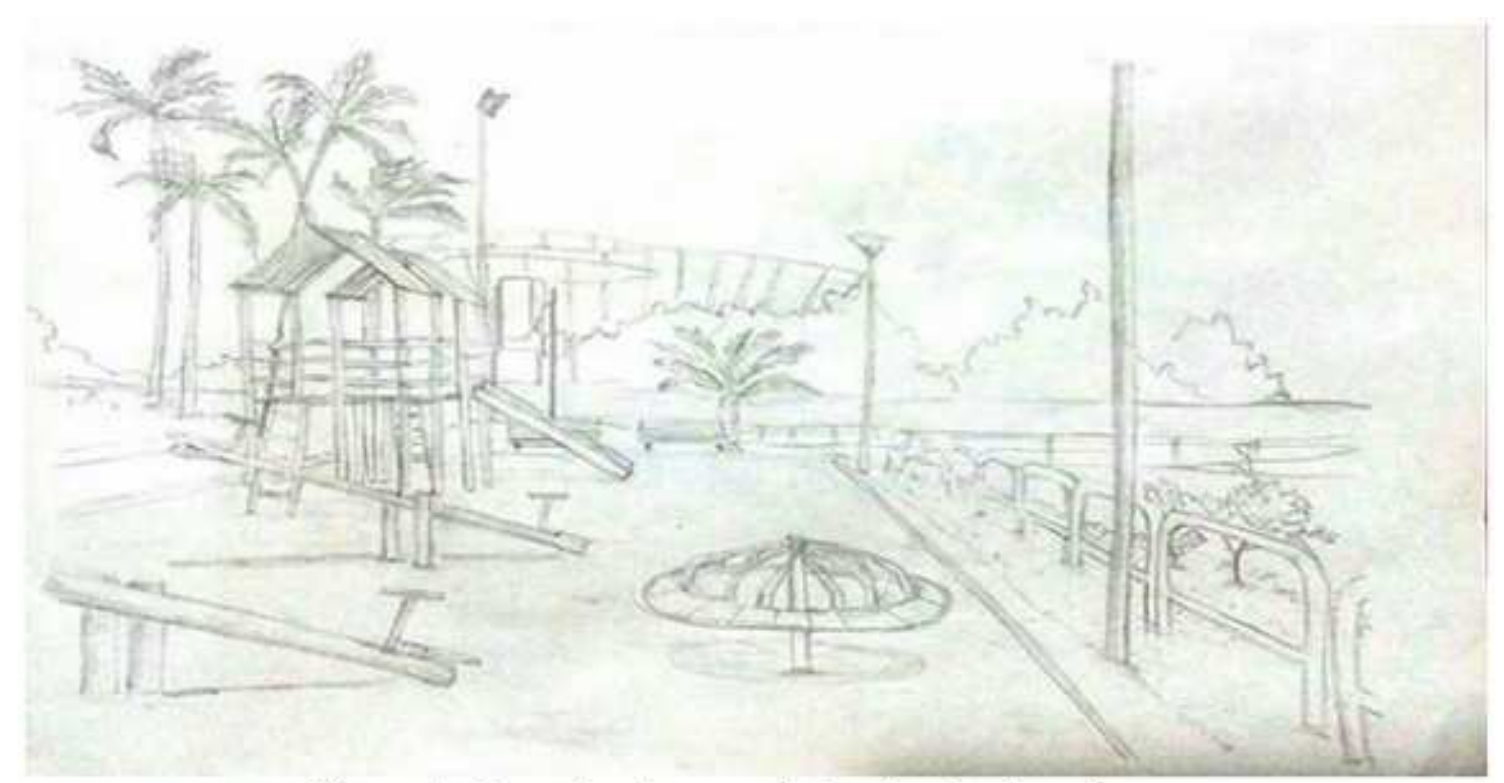

Figura 2: Desenho do parquinho depois da reforma. Ilustração: Mariana L. L. Q. Fonseca

A partir da coleta dos dados físicos e arquitetônicos do referido espaço, constatou-se que antes da reforma havia uma série de 
inadequações e defeitos nos equipamentos, tais como ausência de amortecedores na base das gangorras (ou a danificação dos mesmos, quando presentes); ausência de apoio de mão na gangorra (apenas uma gangorra possuía, em uma de suas extremidades, o apoio de mão). Após a reforma tais danificações foram consertadas, embora algumas falhas estruturais relacionadas às condições de acessibilidade e inclusão tenham permanecido inalteradas, tais como a regulagem de altura e peso, acesso de passagem para cadeirantes, dentre outras. No primeiro caso, considera-se o espaço como desestruturado, haja vista suas inadequações para o uso infantil. No segundo, considera-se o espaço mais estruturado, ou seja, mais adequado para o uso dos brincantes, embora a permanência algumas características arquitetônicas inadequadas ainda representem limitações importantes para a exploração do usuário (ausência de regulagem de peso e altura, etc.).

Em ambas as etapas foram realizadas sessões de observações de brincadeiras. Foram realizadas 10 sessões, cada uma de 30 minutos, com 10 crianças diferentes. As crianças observadas no período anterior à reforma do parquinho não foram as mesmas observadas após a reforma do mesmo. Todos os participantes foram selecionados aleatoriamente, no momento em que brincavam ou chegavam ao parquinho. Em ambas as etapas, o sexo dos participantes foi equivalente ( 5 meninos e 5 meninas), sendo a idade variada entre 2 e 12 anos de idade, uma média geral de 7 anos de idade.

No momento em que cada observação se iniciou, foram considerados todos os tipos de brincadeiras desenvolvidas pela criança, incluindo as de uso criativo. O objetivo da observação consistiu em analisar 0 desenvolvimento da brincadeira criativa diante do uso que a criança fazia do espaço em geral, com ênfase no uso criativo. Foi anotado, de forma pontual e sem análise prévia, cada movimento realizado pela criança no período de observação. O tempo de duração de cada brincadeira desenvolvida durante a sessão de observação não foi cronometrado, sendo a frequência das brincadeiras analisada pela quantidade de vezes que a criança se empenhou em realizá-la, o que foi possível devido a anotação dos movimentos realizados pela criança nesse período. Em ambas as etapas, foram coletados dados sobre o espaço físico do parquinho.

Todos os equipamentos que constituíam o parquinho possuíam funções originais e pré-determinadas: (1) Os módulos estimulavam a brincadeira de faz-de-conta; (2) a gangorra servia para que duas crianças brincassem juntas de subir e descer através de seus respectivos impulsos e pesos; (3) o escorregador era utilizado por uma criança para descer, escorregando, pela rampa de madeira; (4) a barra de ferro funcionava como um apoio para que a criança deslizasse através dela; (5) o carrossel era um equipamento que servia para uma ou mais crianças brincarem de girar. 
Os dados coletados foram analisados qualitativamente através da construção de categorias e análise de conteúdo, em função dos objetivos específicos da pesquisa. Foram realizadas comparações entre brincadeiras criativas desenvolvidas antes e após a reforma do espaço. A pesquisa foi aprovada por um Comitê de Ética através do direcionamento da Plataforma Brasil, tendo sido realizada entre dezembro de 2014 e junho de 2015, no Programa de Iniciação científica do curso de Psicologia da UNIFACS. Todos os participantes envolvidos assinaram um Termo de Consentimento Livre e Esclarecido (TCLE), no caso dos pais elou responsáveis; e um termo de assentimento, no caso das crianças, ambos autorizando participação na pesquisa. Os nomes das crianças apresentados na seção de resultados são fictícios.

\section{Resultados e discussões}

O parquinho estudado nessa pesquisa pertence a um parque público que é um ponto turístico do município de Salvador (BA), sendo também um espaço de lazer constituído por bastante área verde, uma represa - a qual é utilizada para a prática de pedalinho -, um píer - muito usado para a pescaria -, área livre para caminhadas, dentre outros, além do referido parquinho.

A avaliação dos aspectos físico-arquitetônicos e de preservação dos equipamentos do parquinho, antes e após a reforma, é apresentada no quadro 1, onde utilizou-se as normas da Associação Brasileira de Normas Técnicas (ABNT - NBR 14350) como parâmetro: 


\begin{tabular}{|c|c|c|}
\hline Equipamentos & Antes da reforma & Depois da reforma \\
\hline $\begin{array}{l}\text { Módulos/ } \\
\text { Casiaha }\end{array}$ & Adequado & Adequado \\
\hline Escada & $\begin{array}{l}\text { Sem regulagem de } \\
\text { altura/argura, sem corrimäo }\end{array}$ & $\begin{array}{l}\text { Sem regulagem de } \\
\text { altura/largura; sem conimão }\end{array}$ \\
\hline Escorregadores & $\begin{array}{l}\text { Superficie lisa; proteçolo lateral } \\
\text { adequada; pintura desgastada; } \\
\text { sem amortecedor na base }\end{array}$ & $\begin{array}{l}\text { Superficie lisa; proteçào } \\
\text { lateral adequada; pintura } \\
\text { renovada; sem amortecedor } \\
\text { na base }\end{array}$ \\
\hline Barra de ferro & Sem danificaçòes & Sem danificaçôes \\
\hline Carrossel & Näo se aplica & $\begin{array}{l}\text { Colorido, de bom } \\
\text { funcionamento }\end{array}$ \\
\hline Ponte & $\begin{array}{l}\text { Corrimio e piso adequados; } \\
\text { pintura desgastada }\end{array}$ & $\begin{array}{l}\text { Corrimão e piso adequados; } \\
\text { pintura renovada }\end{array}$ \\
\hline Gangorras & $\begin{array}{l}\text { Assentos e apoios de mĩo } \\
\text { quebrados; amortecedores } \\
\text { danificados/ausentes; sem } \\
\text { regulagem de altura e peso, } \\
\text { emissalo de sons estranhos; sem } \\
\text { proteçào lateral }\end{array}$ & $\begin{array}{l}\text { Assentos, apoios de matoe } \\
\text { amortecedores adequados; } \\
\text { sem regulagem de altura e } \\
\text { peso, sem proteçalo lateral }\end{array}$ \\
\hline Piso & Estreito; sem danificạ̧ðes & Estreito, sem danificaçōes \\
\hline $\begin{array}{l}\text { Ponte que liga os } \\
\text { módulos }\end{array}$ & Sem danificaçoes & Sem danificaçōes \\
\hline Escad as & $\begin{array}{l}\text { Sem danificaçdes, sem } \\
\text { corrimåo }\end{array}$ & $\begin{array}{c}\text { Sem danificaçós, sem } \\
\text { corrimăo }\end{array}$ \\
\hline
\end{tabular}

Quadro 1: Características do parquinho

Inicialmente, podemos considerar que as condições estruturais, em termos físicos e arquitetônicos do parquinho em geral, e os seus equipamentos, em particular, apresentavam-se bastante precárias antes da reforma, visto que a maioria desses equipamentos possuía algum defeito ou danificação significativa. Em um segundo momento, quando já havia sido realizada a reforma do parquinho, os equipamentos foram consertados, havendo uma melhora significativa do espaço como um todo, além da inclusão de um novo brinquedo, o carrossel. Entretanto, algumas falhas estruturais, tais como regulagem de altura e peso, permaneceram inalteradas. 
Esses dados corroboram com os encontrados por Santos et al. (2014) em sua pesquisa sobre condições de acessibilidade, segurança e atratividade em parquinhos públicos, uma vez que as autoras relataram que esses espaços não eram acessíveis à toda a população, apresentando déficits importantes em aspectos de segurança, como, por exemplo, a altura dos brinquedos, bem como a baixa atratividade do parquinho, especialmente no que diz respeito às cores, formas e variedade de brinquedos. Tais fatores tiveram relação direta com as brincadeiras observadas na referida pesquisa.

Falando sobre o uso criativo de espaços e equipamentos em geral, sejam eles brinquedos ou não, pode-se dizer que se trata de uma prática bastante comum no universo infantil. Esse uso acontece no momento em que a criança se apropria do espaço em que está inserida de acordo com a sua subjetividade, ou seja, de forma personalizada e diferenciada. Através de um movimento de dupla troca, no qual a criança transforma e é transformada, atribui-se um significado particular a esse espaço (Corsaro, 2011; Pol, 1996; Vygotsky, 1998), que gera, na criança, um senso de identidade que permite o reconhecimento simbólico daquele espaço como seu. Nesse processo, a criança passa a experimentar o espaço de uma maneira característica, própria e diferenciada, devido ao significado pessoal atribuído ao mesmo (Pinto\& Bichara, 2014).

Um fator de relevância nesse processo é a Zona Lúdica, que é o espaço onde a brincadeira acontece, o qual é determinante tanto no desenvolvimento quanto na tipificação das brincadeiras (Bichara, 2005). No caso dos parquinhos públicos, a quantidade, variedade e qualidade de equipamentos (brinquedos), a área livre circunscrita aos mesmos, as cores, a distribuição geográfica e o nível de atratividade dos brinquedos são fatores determinantes no modo de exploração e experimentação do espaço. Assim, é possível compreender a diferença do uso criativo no parquinho desestruturado, aquele com falhas estruturais e equipamentos danificados, e no espaço funcional, ou seja, adequado para o uso infantil.

De acordo com as observações realizadas no parquinho antes e após a reforma, notou-se que, de uma maneira geral, as brincadeiras predominantes foram as criativas e de esforço físico, tais como escorregar e pular, embora outras brincadeiras desse tipo, como correr, saltar, esconder e outras que requeriam maior espaço físico, foram menos frequentes. Além disso, constatou-se que brincadeiras de regras, de faz-de-conta e outras que demandavam maior interação social foram menos comuns.

Esses dados podem estar relacionados ao baixo nível de interação social estabelecido entre as crianças e ao fato da área livre do parquinho ser bastante limitada, mesmo após a sua reforma, o que dificultava a exploração mais livre do espaço. Tais resultados são compatíveis com os encontrados no estudo de Fiaes, Marques, Cotrim 
e Bichara (2010), o qual revelou que brincadeiras de faz-de-conta e brincadeiras de regras se desenvolvem mais quando o espaço circunscrito ao parquinho é mais amplo. Outro resultado que se apoia nesse estudo diz respeito ao predomínio de brincadeiras de exercício físico, resultado de uma maior concentração de brincadeiras nos equipamentos do parquinho.

Em uma perspectiva mais específica, ao analisar-se as brincadeiras antes da reforma do parquinho, observou-se que o uso criativo foi mais predominante devido à danificação e à falta de manutenção dos equipamentos, bem como à pouca quantidade e variedade de brinquedos, além da baixa atratividade destes. Neste espaço estimulantemente limitado e empobrecido, as crianças recorriam à utilização de estratégias de exploração baseadas na apropriação do espaço para experimentar os brinquedos. O quadro 2 contém trechos de observações que exemplificam as principais estratégias observadas antes da reforma do parquinho:

\begin{tabular}{|c|c|}
\hline Estratégia de exploraçào do espaço & Exemplo \\
\hline Combinaçâo de açōes & $\begin{array}{l}\text { "Vai para a gangorra, apoia-se nos assentos para } \\
\text { movimentar a gangorra para cima e para baixo com } \\
\text { as milos; sii da gangorra, pega impulso ea } \\
\text { atravessa de um lado a outro correndo. Em seguida, } \\
\text { apoia as pernas cm seu ligamento de madeira, } \\
\text { fieando pendurado na gangorna. Solta as pemas e } \\
\text { continua se segurando na gangoma; solta os tracos, } \\
\text { deita no chäo e sorri quando a mâe pede para ele } \\
\text { parar de brincar daquela forma" (Otivio, } 7 \text { anos) }\end{array}$ \\
\hline Ressignificaçào do espaço & $\begin{array}{l}\text { "Vai para a gangorra e apoia os pés no assento, } \\
\text { ficando "détada" no ligamento de madeira da } \\
\text { gangorra, segurando-se no eixo central" (Carnala, } 6 \\
\text { tanos) }\end{array}$ \\
\hline Arriscar-se & $\begin{array}{l}\text { "Vai para a gangorra, segura o assento com as màos } \\
\text { eo balanga repetidas vezes; distancia-se da } \\
\text { gargorna, pega impul so e corre em direçào a } \\
\text { gangorra, atravessmdo-a como se fosse uma ponte" } \\
\text { (Caio, } 8 \text { anos) }\end{array}$ \\
\hline Experimentaçào do novo & $\begin{array}{l}\text { "Sobe no móculo pela escorregadeina e senta no } \\
\text { ehào; apcia a parte de trás do joelho no chaso do } \\
\text { módulo e fica de porta-cabega; segura-se no chío } \\
\text { do módulo e ergue-se novamente, voltando a descer } \\
\text { pela esconregadeira. (Mauricio, } 9 \text { anos) }\end{array}$ \\
\hline
\end{tabular}

Quadro 2: Exemplos de estratégias de exploração do parquinho antes da reforma 
De acordo com o quadro 2 nota-se que a variação da função original dos equipamentos é muito significativa, revelando a expressão da criatividade da criança e a sua capacidade de construir novas possibilidades diante do espaço desestruturado, o que favorece suas habilidades de adaptação. Assim, a criança aumenta seu repertório comportamental e desenvolve maior autonomia diante do ambiente no qual se encontra.

Ao descobrir novas possibilidades de utilização do brinquedo, a criança ignora sua função original e o transforma em um objeto com múltiplas funções, que pode ser utilizado de acordo com seu desejo e interesse. Isso acontece, por exemplo, quando a gangorra é transformada em uma ponte e quando do escorregador surge uma rampa de subida para os módulos; ou ainda quando a apropriação do espaço ocorre de uma forma alternativa, como quando a criança entra no carrossel por baixo do assento, através das ferragens. Estes exemplos ilustram a transformação que a criança faz do "espaço para criança" em "espaço de criança" (Rasmussen, 2004).

Diante disso, pode-se concluir que na primeira etapa da pesquisa 0 uso criativo se desenvolveu devido às danificações dos equipamentos, mesmo que isso representasse um grave risco de acidente para as crianças. Considera-se que o uso dos equipamentos danificados representa um risco à saúde da criança, uma vez que esta se engaja em brincadeiras perigosas e explora equipamentos mesmo quando suas condições estruturais se apresentam inadequadas para a finalidade. Esse dado chama atenção, uma vez que implica riscos de acidente para o brincante, especialmente se não houver supervisão adequada. Isso ainda é reforçado quando se pensa que mesmo em perfeitas condições estruturais, os acidentes em parquinhos podem acontecer.

Estima-se que $88 \%$ dos acidentes em parquinhos públicos se devem a quedas por brinquedos de agilidade física, tais como a gangorra, sendo as demais causadas por colisões nos escorregadores com superfícies danificadas. Além disso, aproximadamente $40 \%$ dos acidentes nesse contexto resultam de supervisão inadequada dos adultos (Harada, Pedreira \& Andreotti, 2003).

Em seu estudo sobre acessibilidade em parquinhos, Corrêa e Manzini (2010) mostraram que grande parte dos brinquedos destes espaços não apresentavam bons aspectos de segurança, na medida em que não possuíam alguns de seus elementos fundamentais, tais como cinto de segurança nas gangorras, grades de proteção no escorregador, isolamento e/ou retirada de brinquedos danificados, dentre outros, ressaltando a importância da manutenção desses espaços no intuito de evitar que acidentes possam acontecer.

Outro estudo selecionou alguns parquinhos infantis para observação no intuito de verificar acidentes ocorridos com crianças nesses locais. Posteriormente, algumas medidas básicas de segurança foram 
implantadas nesses espaços e, após as intervenções, constatou-se que os acidentes foram reduzidos em aproximadamente 2,5 vezes (Silbert, Mott, Rolf, James, Evans \& Kemp et al., 1999 citado por Harada, Pedreira \& Andreotti, 2003). Esses dados servem de alerta para as instâncias governamentais em relação à implementação de medidas que garantam a segurança das crianças nesses espaços e convidam a comunidade científica a desenvolver mais estudos sobre 0 tema contemplando a realidade brasileira.

Ainda falando sobre brincadeiras antes da reforma, o quadro 3 ilustra os tipos que foram mais comuns durante as observações, considerando também a faixa-etária e sexo dos brincantes.

\begin{tabular}{|c|c|c|c|c|}
\hline $\begin{array}{c}\text { Equipamento } \\
\text { / Espaço }\end{array}$ & Brincadeira desenvolvida & $\begin{array}{c}\text { Tipo de } \\
\text { brincadeira }\end{array}$ & $\begin{array}{l}\text { Faixa- } \\
\text { etária }\end{array}$ & Sexo \\
\hline Gangorra & $\begin{array}{l}\text { Usada como rampa de } \\
\text { passagem e como balanço } \\
\text { por mais de uma criança }\end{array}$ & $\begin{array}{l}\text { Esforço } \\
\text { fisico e } \\
\text { criativa }\end{array}$ & $\begin{array}{l}7 \text { a } 10 \\
\text { anos }\end{array}$ & $\begin{array}{l}\text { Meninos e } \\
\text { meninas }\end{array}$ \\
\hline Escorregador & $\begin{array}{l}\text { Usada como rampa de } \\
\text { subida e para escorregar }\end{array}$ & $\begin{array}{l}\text { Esforço } \\
\text { fisico e } \\
\text { criativa }\end{array}$ & $\begin{array}{c}\text { Idades } \\
\text { variadas }\end{array}$ & $\begin{array}{c}\text { Meninos e } \\
\text { meninas }\end{array}$ \\
\hline Piso & $\begin{array}{l}\text { Usado para brincadeiras } \\
\text { manuais (fazer comidinha, } \\
\text { castelo, bonecos, etc.) }\end{array}$ & Criativa & $\begin{array}{l}2 \text { à } 5 \\
\text { anos }\end{array}$ & $\begin{array}{l}\text { Geralmente } \\
\text { meninas }\end{array}$ \\
\hline $\begin{array}{l}\text { Módulos / } \\
\text { Casinhas }\end{array}$ & $\begin{array}{c}\text { Usado para apoiar a fossa } \\
\text { poplitea nas barras de } \\
\text { madeira e ficar de ponta- } \\
\text { cabeça }\end{array}$ & $\begin{array}{l}\text { Esforço } \\
\text { fisico e } \\
\text { criativa }\end{array}$ & $\begin{array}{l}7 \text { a } 10 \\
\text { anos }\end{array}$ & $\begin{array}{c}\text { Geralmente } \\
\text { meninos }\end{array}$ \\
\hline Escada & $\begin{array}{l}\text { Usada para subir, descer de } \\
\text { costas, para passar por } \\
\text { "dentro" dos degraus }\end{array}$ & $\begin{array}{l}\text { Esforço } \\
\text { fisico e } \\
\text { criativa }\end{array}$ & $\begin{array}{l}5 \text { a } 7 \\
\text { anos }\end{array}$ & $\begin{array}{c}\text { Meninos e } \\
\text { meninas }\end{array}$ \\
\hline Barra de ferro & $\begin{array}{l}\text { Usado para escorregar e } \\
\text { subir no módulo }\end{array}$ & $\begin{array}{l}\text { Esforço } \\
\text { físico e } \\
\text { criativa }\end{array}$ & $\begin{array}{l}5 \text { a } 10 \\
\text { anos }\end{array}$ & $\begin{array}{c}\text { Geralmente } \\
\text { meninos }\end{array}$ \\
\hline
\end{tabular}

Quadro 3: Brincadeiras mais comuns desenvolvidas no parquinho antes da reforma

Observa-se que todos os brinquedos antes da reforma foram utilizados de maneira criativa, embora não de forma exclusiva, o que reflete o interesse da criança em explorar o espaço de forma variada, incluindo também a convencional. Constata-se que, de modo geral, houve pouca diferenciação entre o uso dos equipamentos e o sexo dos brincantes, sendo estas relacionadas às brincadeiras mais exóticas, como apoiar a fossa poplítea nas barras de madeira da casinha e ficar de ponta-cabeça. Também não houve discrepância significativa em relação à variação de idade e uso dos equipamentos, exceto em relação às brincadeiras manuais, que foram predominantemente executadas por crianças mais novas (quadro 3 ). 
Após a reforma do parquinho, notou-se que as brincadeiras criativas permaneceram quase inalteradas, havendo diferenciação apenas em relação à gangorra, conforme exemplificado no quadro 4 .

\begin{tabular}{|c|c|c|}
\hline $\begin{array}{c}\text { Equipamentos } \\
\text { / brinquedos }\end{array}$ & $\begin{array}{l}\text { Principais brincadeiras criativas } \\
\text { antes da reforma do parquinho }\end{array}$ & $\begin{array}{l}\text { Principais brincadeiras } \\
\text { criativas depois da reforma do } \\
\text { parquinho }\end{array}$ \\
\hline Gangorra & $\begin{array}{l}\text { Usada como rampa de passagem } \\
\text { Usada como balanço coletivo } \\
\text { Usada para ser empurrada para } \\
\text { cima e para baixo com as måos }\end{array}$ & $\begin{array}{l}\text { Usada para ser empurrada para } \\
\text { cima e para baixo com as mâos }\end{array}$ \\
\hline Carrossel & Não se aplica & $\begin{array}{l}\text { Usado para ser girado com as } \\
\text { måos, e de formas diferenciadas (a } \\
\text { criança em pe, ajoelhada no } \\
\text { assento, etc.) }\end{array}$ \\
\hline Escorregador & $\begin{array}{l}\text { Usada para descer de bruços'de } \\
\text { lado e como rampa de subida }\end{array}$ & $\begin{array}{l}\text { Usada para descer de bruçoside } \\
\text { lado e como rampa de subida }\end{array}$ \\
\hline $\begin{array}{c}\text { Piso } \\
\text { Módulo }\end{array}$ & $\begin{array}{l}\text { Usado para brincadeiras manuais } \\
\text { Usado para apoiar a fossa poplitea } \\
\text { nas barras de madeira e ficar de } \\
\text { ponta-cabeça }\end{array}$ & $\begin{array}{c}\text { Usado para brincadeiras manuais } \\
\text { Usado para apoiar a fossa poplitea } \\
\text { nas barras de madeira e ficar de } \\
\text { ponta-cabeça }\end{array}$ \\
\hline Escada & $\begin{array}{l}\text { Usada para entrar e sair por dentro } \\
\text { dos degraus }\end{array}$ & $\begin{array}{c}\text { Usada para entrar e sair por dentro } \\
\text { dos degraus }\end{array}$ \\
\hline Ponte & Usada para pular e dançar & Usada para pular e dançar \\
\hline Barra de ferro & $\begin{array}{c}\text { Usada para subir no módulo e para } \\
\text { se pendurar }\end{array}$ & $\begin{array}{l}\text { Usada para subir no módulo e } \\
\text { para se pendurar }\end{array}$ \\
\hline
\end{tabular}

Quadro 4: Brincadeiras criativas mais comuns antes e depois da reforma do parquinho

É possível perceber que a gangorra foi o brinquedo mais explorado através do uso criativo antes da reforma. Após a reforma, a maior parte do uso criativo que se fazia dela tornou-se impossível devido à reparação das suas danificações (as quais possibilitavam este uso). Desse modo, a gangorra se tornou um brinquedo mais estruturado e menos arriscado/perigoso para os brincantes. O escorregador e 0 carrossel, por sua vez, tornaram-se os brinquedos mais utilizados de forma criativa. A permanência de brincadeiras criativas após a reforma nos permite compreender que a criatividade faz parte da infância, uma vez que o brincante não reproduz apenas aquilo que vê, mas transforma a realidade constantemente, tendo um papel ativo em seu processo de desenvolvimento ao se apropriar dos espaços por elas ocupados (quadro 4).

O uso criativo continuou sendo predominante em relação aos demais tipos de brincadeira após a reforma, mas não esteve mais associado com as danificações dos equipamentos, o que representa um grande 
avanço em termos de segurança para os brincantes. Um exemplo disso refere-se à extinção de uma brincadeira na qual as crianças se subdividiam em grupos e faziam o compartilhamento da gangorra, utilizando-a como um grande balanço coletivo (o que era possível devido à ausência de apoios de mão), -no qual algumas crianças sentavam nos assentos enquanto outras se posicionavam no ligamento de madeira que -conectam os dois assentos.

Após a reforma do parquinho, as crianças começaram a se implicar mais no jogo funcional, uma vez que havia condições para isso. O jogo técnico também foi observado, já o jogo social não muito. De acordo com Borges (2008), as brincadeiras e os jogos realizados no contexto dos parquinhos públicos se desenvolvem em fases. Primeiramente, acontece jogo funcional, momento em que a criança utiliza o equipamento de forma convencional, de acordo com sua função original. Essa fase se estende por tempo indeterminado, podendo acontecer várias vezes até que a criança assimile o equipamento de modo que o convencional se torne desinteressante. Em um segundo momento, ocorre o jogo técnico, momento em que a criança começa a criar a sua própria maneira de explorar o equipamento, de forma diferente e alternativa ao uso convencional do mesmo. É nessa fase que, por exemplo, o brincante faz da gangorra uma ponte ou gira o carrossel com as mãos. A terceira fase, o jogo social, a criança transforma o equipamento em um objeto de socialização. Este, por sua vez, se torna o meio onde a brincadeira acontece; é quando a interação social entre as crianças é fortalecida. Considera-se que o jogo técnico e o jogo social são formas de brincadeiras criativas.

Além disso, notou-se que antes da reforma do parquinho acontecer, as crianças variavam mais as brincadeiras e o uso dos equipamentos. A frequência da modificação de brincadeiras, bem como de troca de equipamentos, foi mais significativa nesse período de observação. Após a reforma, a frequência do uso dos equipamentos foi modificada, pois as crianças passaram a se entreter mais em um mesmo brinquedo ou brincadeira antes de se engajar em uma brincadeira ou equipamento diferente. Esse dado pode ser observado nos seguintes trechos de observação realizada, respectivamente, antes e depois da reforma do parquinho:

Sobe no módulo pela escorregadeira, vai para a ponte, pula repetidas vezes e volta para a escorregadeira, descendo e batendo os pés. Vai para a gangorra, balançando-a para cima e para baixo com as mãos. Segue para o módulo e segura no chão do módulo, apoiando-se para tirar os pés do chão e se balançar (Ricardo, 9 anos). 
Nesse trecho, nota-se que o brincante se implica pouco e/ou menos na exploração de-um mesmo equipamento, uma vez que varia mais o uso dos brinquedos, indo de um para o outro com bastante frequência.

Gira no carrossel junto com o pai; Sobe no carrossel e gira; freia o carrossel com as pernas e gira o carrossel para o outro lado. Vai para a escorregadeira, subindo por ela como se fosse uma ponte e depois desce pausadamente; sobe novamente pela escorregadeira e desce devagar, parando no meio da escorregadeira para voltar a subi-la, de costas e sentada (Luana, 6 anos).

No segundo trecho, observa-se que o brincante ainda varia bastante o uso dos equipamentos, mas explora o mesmo equipamento um pouco mais antes de trocar. Estes resultados são compartilhados pela pesquisa de Luz e Kuhnen (2013), que constataram que o modo como as crianças se apropriavam do espaço e desenvolviam brincadeiras estava diretamente relacionado às características estruturais do parquinho, bem como à presença de brinquedos e sua manutenção. Da mesma forma, as autoras perceberam que os brincantes se mantinham engajados em uma mesma atividade e interagiam mais em espaços estruturados, constituídos de equipamentos mais atrativos e multifuncionais do que os tradicionais; e que, nos ambientes menos estruturados, a diversidade de brincadeiras era mais notória, visto que a criança permanecia numa mesma atividade durante menos tempo.

Ao falar de apropriação de espaços e de brincadeiras, fala-se também de cultura. O fato de não dispor de nenhum comportamento específico que permita a distinção do que consiste ou não uma atividade lúdica (Bruner, 1983 citado por Brougére, 1998), o brincar se caracteriza como um exercício de aprendizagem da própria brincadeira. Na medida em que vai compreendendo o significado fictício da brincadeira, a troca de papeis, a repetição e as regras de jogo (Bruner, 1983 citado por Brougére, 1998), a criança passa a se apropriar não somente do espaço em que a brincadeira se desenvolve, mas também da cultura que rege essa brincadeira.

Adicionalmente, ao pensarmos que a cultura do meio em que a criança está inserida se relaciona à produção de brincadeiras (Brougére, 1998), entende-se que estas se configuram como uma maneira da criança participar da sua própria construção cultural em um nível mais amplo. Enquanto sujeito social, a criança produz uma cultura lúdica no momento que brinca e reflete essa produção em sua postura ativa no processo de inserção e desenvolvimento social. Desse modo, a brincadeira se torna um veículo de acesso à cultura e de socialização. 
Tratando-se especificamente do uso criativo, pensar que a criação e inovação de brincadeiras mediante o uso de diversas estratégias de apropriação do espaço possibilita à criança construir uma cultura lúdica com significados pessoais e próprios dentro de um contexto cultural mais amplo e heterogêneo, reforça a ideia defendida por Corsaro (2011) de que a criança é um sujeito social ativo na promoção, transformação e reprodução cultural do meio em que está inserida uma vez que a criatividade no brincar expressa essa representação.

\section{Considerações finais}

De modo geral, foi possível verificar que o uso criativo acontece em qualquer contexto de desenvolvimento, haja vista a sua prevalência tanto antes quanto após a reforma do parquinho. De acordo com os resultados, notou-se que em espaços mais estruturados, onde não há danificações dos equipamentos, as crianças tendem a explorar os equipamentos de forma funcional antes de iniciarem o uso criativo; e que, em espaços menos estruturados, cujos equipamentos apresentam danificações, o uso criativo já é realizado inicialmente, uma vez que o jogo funcional não é possível. Além disso, notou-se que nestes espaços a frequência. Assim, é preciso que as instâncias públicas considerem essa realidade e busquem ampliar a regularidade de manutenção desses espaços que são fundamentais para o desenvolvimento das crianças. Nesse sentido, é possível pensar em algumas medidas que favoreçam o uso criativo dos parquinhos sem que isso represente um risco para as crianças, tais como aumentar a quantidade, variedade e atratividade dos brinquedos; disponibilizar área livre mais ampla, no intuito de favorecer a interação social entre os brincantes e incluir brinquedos multifuncionais e menos diretivos e/ou rígidos em sua função original, que favoreçam a expressão e o exercício da criatividade.

Acredita-se que os resultados obtidos nesta pesquisa são importantes para uma compreensão mais aprofundada sobre o desenvolvimento do uso criativo, considerando a sua importância dentro do universo infantil. Uma das limitações deste estudo se refere à quantidade de episódios de brincadeira observadas nas duas etapas da pesquisa e ao fato das brincadeiras criativas não terem sido cronometradas. Contudo, os resultados aqui obtidos podem ser ampliados por meio da sua continuidade e pelo aperfeiçoamento da coleta de dados. É preciso ressaltar a importância de uma maior produção científica voltada para essa temática, haja vista o pouco referencial teórico existente no campo da Psicologia sobre o assunto. 


\section{Referências}

Associação Brasileira de Normas e Técnicas (1999). NBR 14350-1: Segurança de brinquedos de playground. Parte 1: Requisitos e métodos de ensaio. Rio de Janeiro - RJ.

Bichara, I. D. (2005). Apropriação e ressignificação de espaços e equipamentos públicos: Um outro ângulo para o estudo dos contextos de brincadeiras. In L. Souza \& Z. A. Trindade (Eds.), Simpósio Nacional de Psicologia Social e do Desenvolvimento \& $X$ Encontro Nacional do Programa Nacional de Cooperação Acadêmica - Psicologia. Violência e desenvolvimento humano: Textos completos (pp. 28-36). Vitória, ES: Universidade Federal do Espírito Santo.

Bichara, I. D., Lordelo, E. R., Carvalho, A. M. A., \& Otta, E. (2009). Brincar ou brincar: eis a questão - a perspectiva da psicologia evolucionista sobre a brincadeira. In E. Otta; M. E. Yamamoto (Orgs.), Psicologia Evolucionista (pp.104-113). Rio de Janeiro: Guanabara Koogan

Bjorklund, D. F. (1997). The role of immaturity in human development. Psychological Bulletin, 122, 153-169. http://dx.doi.org/10.1037/0033-2909.122.2.153.

Borges, M. (2008). Diretrizes para Projetos de Parques Infantis Públicos.(Dissertação de mestrado).Programa de PósGraduação em Arquitetura e Urbanismo, Universidade Federal de Santa Catarina, Santa Catarina.

Brougère, G. (1998). A criança e a cultura lúdica. Revista da Faculdade de Educação, 24(2), 103-116. http://dx.doi.org/10.1590/S0102-25551998000200007.

Corrêa, P. M., \& Manzini, E. J. (2010). Acessibilidade em parque infantil: um estudo em escolas de educação infantil. $33^{\circ}$ Reunião Anual da ANPEd, Caxambu/MG. Disponível em: http://33reuniao.anped.org.br/33encontro/app/webroot/files/fil e/Trabalhos\%20em\%20PDF/GT07-6088--Int.pdf

Corsaro, W. (2009). Reprodução interpretativa e Cultura de pares. In Muller, F., \& Carvalho, A. (Org.). (2012). Teoria e prática na pesquisa com crianças: diálogos com William Corsaro. São Paulo: Cortez.

Corsaro, W. A. (2011). Sociologia da infância. Porto Alegre: Artmed.

Cotrim, G. S., \& Bichara, I. D. (2013). Brincar no ambiente urbano: limites e possibilidades em ruas e parquinhos de uma metrópole.Psicologia: Reflexão e Crítica. 26(2),388-395. Disponível

em: http://www.redalyc.org/articulo.oa?id=18827804019.

Fagen, R. (1981). Animal play behavior. New York: Oxford Unversity Press. DOI: 10.1002/ajpa.1330580117. 
Fiaes, C. S., Marques, R. L., Cotrim, G. S., \& Bichara, I. D. (2010). Gênero e brincadeira em parquinhos públicos de Salvador (BA). Interação em Psicologia, 14(1), 31-41. http://dx.doi.org/10.5380/psi.v14i1.13465.

Harada, M. J. C. S., Pedreira, M. L. G., \& Andreotti, J. T. (2003) Segurança com brinquedos de parques infantis: uma introdução ao problema. Revista Latino-Americana de Enfermagem, 11(3), 383-386. http://dx.doi.org/10.1590/S010411692003000300018.

Johnson, J., Christie, J., \& Yawkey, T. (1999). Play and early childhood development. New York: Longman.

Luz, G. M. \& Kuhnen, A. (2013). O Uso dos Espaços Urbanos pelas Crianças: Explorando o Comportamento do Brincar em Praças Públicas. Psicologia: Reflexão e Crítica, 26(3), 552-560. Disponível em: <http://dx.doi.org/10.1590/S010279722013000300015>

Luz, G. M., Raymundo, L. S., \& Kuhnen, A. (2010). Uso dos espaços urbanos pelas crianças: uma revisão. Psicologia: teoria e prática. 12(3), 172-184. Disponível em: <http://pepsic.bvsalud.org/scielo.php?pid=S151636872010000300014\&script=sci_arttext $>$.

Moraes, M. S., \& Otta, E. Entre a serra e o mar. (2003). In Carvalho, A., Magalhães, C., Pontes, F., \& Bichara, I. (Eds.). Brincadeira e cultura: viajando pelo Brasil que brinca. (p. 127-1576). São Paulo: Casa do Psicólogo.

Niemeyer, C. A. C. (2005). Uma contribuição para a pesquisa em história do paisagismo: Os parques infantis e as ressonâncias da tipologia reformpark em São Paulo. Paisagens em debate. Revista Eletrônica da Área Paisagem e Ambiente. Disponível em:

http://www.fau.usp.br/depprojeto/gdpa/paisagens/artigos/200 5Niemeyer-ParquesIfantis.pdf

Oliveira, C. (2004). O ambiente urbano e a formação da criança. São Paulo: Aleph.

Pellegrini, A, \& Smith, P. (1998). The development of play during childhood: form and possible functions. Child Psychology and Psychiatry. 3(2), 51-57. http://journals.cambridge.org/article_S1360641798001476.

Pinto, P. S. P., \& Bichara, I. D. (2014) Concepções e ações de crianças a respeito dos espaços públicos onde brincam: um foco na criança cidadã. II Simpósio luso-brasileiro de estudos com crianças. Faculdade de Educação da Universidade Federal do Rio Grande do Sul, Porto Alegre, RS.

Pol, E. (1996). La apropiación en la escuela. In Iñiguez, L., \& Pol, E. (Coords.), Monografies Psico/Socio/Ambientals: Cognición, 
representación y apropición del espacio. (9), 45-62. Barcelona: Publicacions Universitat de Barcelona.

Rasmussen, K. (2004). Places for children - Children's places. Childhood 11(2), 155-173. DOI: 10.1177/0907568204043053.

Santos, N. A., Nascimento, C. B. R., \& Pinto, P. S. P. (2014) Perspectivas acerca de parquinhos públicos quanto à acessibilidade, atratividade e segurança. Seminário Estudantil de Produção Acadêmica. 13. Disponível em: http://revistas.unifacs.br/index.php/sepa/article/view/3390.

Seixas, A. A. C., Becker, B. \& Bichara, I. D. (2012). Reprodução interpretativa e cultura de pares nos grupos de brincadeira da Ilha dos Frades/BA. Psico, 43(4). Disponível em: http://revistaseletronicas.pucrs.br/ojs/index.php/revistapsico/a rticle/viewFile/10260/8517.

Siaulys, M. O. C. (2005). Brincar para todos. Brasília: MEC/SEESP. Disponível

em: http://portal.mec.gov.br/seesp/arquivos/pdf/brincartodos.pdf

Spinka, M.; Newberry, R. C.; Bekoff, M. (2001) Mammalian play: Training for the unexpected. Quarterly Review of Biology. 76, 141-168. Disponível em: http://www.jstor.org/stable/2664002.

Vieira, M. L., Sartorio, R. (2002) Análise motivacional, causal e funcional da brincadeira em duas espécies de roedores. Estudos de Psicologia, 7(1), 189-196. Disponível em: http://repositoriodigital.academica.mx/jspui/handle/987654321 /280118.

Vygotsky, L. S. (1998). A formação social da mente. São Paulo: Martins Fontes.

\section{Endereço para correspondência \\ Amanda Santos de Souza}

Universidade Salvador - UNIFACS

Avenida Edgard Santos, 501, Cond. Bosque da Lagoa, Narandiba, CEP 41180-790, Salvador - BA, Brasil

Endereço eletrônico: amandasouza.s@hotmail.com

\section{Paula Sanders Pereira Pinto}

Universidade Salvador - UNIFACS

Avenida Luis Viana, 3100, Campus Professor Barros, CEP 41720-200, Salvador BA, Brasil

Endereço eletrônico: paula.pereira@pro.unifacs.br

Recebido em: 15/06/2016

Reformulado em: 08/09/2016

Aceito para publicação em: 21/11/2016

\section{Notas}

* Estudante de graduação em Psicologia pela Universidade Salvador.

** Dra. em Psicologia do Desenvolvimento (UFBA), Mestre em Saúde Coletiva (UFBA), Psicóloga (UFBA), professora de graduação em Psicologia da Universidade Salvador (UNIFACS). 